paresis, dementia precox, etc. Many of the 19 cases of neuritis had Korsakow's psychosis; the 10 cases of " edema of the brain" (usually a post-mortem diagnosis) were for the most part alcoholic cases with "wet brains," presenting various mental disturbances. Some of the hysterical and epileptic cases, also, had marked mental disturbances, and various other cases were more or less delirious. On the whole it is a safe statement to say that over 100 patients presented, during at least a part of their stay in the hospital, some form of mental disturbance. This disturbance was often transitory, and comparatively few of them were finally committed to a hospital for the insane, but the hospital has cared for a very considerable number of patients in this service for whom a "psychopathic hospital" is urged, and, with a further development of the service, it can care for still more, and must necessarily care for many cases, even after the " psychopathic hospital " is opened.

That the new service has many problems to meet in the future, in the way of administrative detail, and that it needs further development along certain lines, is obvious; it is my object at present merely to indicate what has been done in this first year and to show what opportunities the Boston City Hospital now affords for neurological study and teaching.

\section{THE YOUTHFUL PSYCHOPATH.*}

BY J. W. COURTNEY, M.D., BOsTON.

The purpose of this very brief communication is to stimulate interest in a subject which I believe to be quite as important to the pediatrist as it is to the neurologist. Theoretical considerations I shall endeavor to avoid, for I know you will heartily agree with the statement that we are already surfeited with theories which mark the record for altitude in flights of psychologic fancy.

In textbooks and other writings on the subject of certain psychoses - notably paranoia and dementia precox - and certain psychoneuroses, clinically designated as hysteria and psychasthenia, the statement is frequently made that these disorders are due to factors which become active between the ages of puberty and maturity, and that their outbreak generally takes place between these two periods.

In my opinion this statement is both erroneous and misleading. It is true, to be sure, that the disorders mentioned frequently do not reach their maximum intensity until some time between the ages of sixteen and thirty. But to you who are constantly observing the ailments of infants and young children, it must be a matter of observed fact that unmistakable evidence of the existence of these disorders is very often present at a tender age.

As to causation, I believe you will agree that in practically all cases presenting this early evidence the hereditary origin of the trouble may be readily established. Indeed, actual statistics

* Read at the twelfth meeting of the New England Pediatric Society held in Sprague Hall, Boston Medical I.ibrary, Nov. 26, 1910. show that at least $75 \%$ of the cases representing these adynamic types of nervous and mental disturbance come from families in which mental alienation in some form or other has appeared in more than one generation. It is also an established fact that ancestral alcoholism, tuberculosis and syphilis must be given a prominent place in pathogenesis. Furthermore, it is often found that the father or the mother of the psychasthenic or the hysteric is afflicted with the same trouble and that the patient is apt to bear a strong physical resemblance to the afflicted parent. Finally, it may be stated that even in cases where the immediate forbears have no actual nervous disorder, they nevertheless often present such stigmata of mental and physical insufficiency as timidity, lack of balance and sound judgment, indecision and morbid emotionalism.

From my own personal experience and observation I am convinced that psychasthenia, hysteria, paranoia and dementia precox are identical in pathology and that in the overwhelming majority of cases they are hereditary in origin and slow in evolution. I am furthermore convinced that unequivocal clinical signs of their presence are always observable as early as the fifth year of life - in certain cases even earlier; and it is to the victims of these manifestations that $I$ have applied the not altogether satisfactory term "youthful psychopath."

Assuming that my convictions are well-founded, of what importance are they to the pediatrist? They are of paramount importance, because he is far more apt than either the neurologist or the alienist to come in contact with the afflicted child when the disorder is in its inception or but slightly advanced.

Those of you who are skeptical with regard to the value of neurological therapeutics may ask yourselves what practical results the writer of this paper expects to follow an early recognition of the disorder.

To such my answer is that early recognition offers opportunities for achievement along the lines of prophylaxis and treatment quite as signal and brilliant as any obtained in the combat with tuberculosis.

I venture this assertion because pathology fails to reveal to us that the condition underlying the disorders in question is other than an adynamic one, and with such a condition, even though it be of hereditary origin, we have every reason to hope for a successful struggle.

Before we can put into action our prophylactic and therapeutic forces, however, we must be sure that we thoroughly understand the youthful psychopath mentally, morally, emotionally and physically.

There is nothing absolutely distinctive about the bodily habit of such a child, although it is very apt to have a slender musculature, a narrow chest, scaphoid scapulæ, drooping shoulders and a vascular hypotonicity, with the vasomotor ataxia which so commonly accompanies this lastmentioned condition.

In a certain percentage of cases there is a differ- 
ence in the size of the pupils, most noticeable when the eyes are turned away from the light. The pupils are, nevertheless, always regular in outline, the response to tests of light and distance is prompt and alike in both eyes, and concentric limitation of the field of vision is invariably absent. The remaining sensorial, as well as the sensory, stigmata are also lacking.

Owing to the vasomotor irritability the susceptibility to atmospheric conditions is very marked. If the child happens to be outdoors when the weather is at all cold, its extremities quickly become mottled and painfully cold and numb. If it chances to go indoors while in this condition, the heat of the house very soon causes a change from vasoconstriction to vasodilatation, with the result that the ears, cheeks, hands and feet tingle and grow uncomfortably hot and red.

In many cases the enthusiasm for childish games of the outdoor sort is not in the least abated. On the contrary, they are entered into with intensity and vehemence, but the emotional reaction is so marked that appetite is abolished and sleep is disturbed by vivid dreams. So slight, in fact, is such a child's power of inhibition that after a hard day's play it will toss and tumble about the bed all through the night, grind its teeth, cry out aloud or from time to time mumble disjointed phrases.

In other cases a distinctly anti-social tendency is early exhibited. Where this exists, the child has no desire for outdoor play with other children, but prefers to remain at home with a parent or nurse. Both these types exhibit marked propensities to sleep-walking and similar automatic acts, and also to night-terror and bed-wetting. Furthermore, in both types, again, the eruption a tooth or the onset of even a mild attack of one of the exanthemata is very apt to be ushered in by convulsions.

Intellectually the psychopathic child is, as a rule, precocious to a marked degree, but unfortunately its intellectual nature is so completely overwhelmed by its emotions that, both in school and company, really dull children of its own age appear actually brilliant by comparison.

I should like to make manifest to you the full extent to which the morbid emotionalism of this child overshadows its intellectuality, shapes its character and compels its thoughts and actions, but I confess that my powers of expression are entirely inadequate to perform such a task satisfactorily. However, the facts, although stated in a clumsy and roundabout fashion, are about as follows: One of the most powerful of the elemental human emotions is fear. In proof of this one has merely to observe the expression of this emotion in the newborn infant. No experience hypothesis in explanation of this phenomenon is tenable. Clearly, the fear-emotion is a heritage transmitted by countless generations, and a child comes into the world with it as firmly embedded in the meshes of his brain cells as the deciduous teeth are in the gums. This is true of even the most normal child, but is infinitely truer of the adynamic. Weakness and fear go hand in hand, and in the youthful psychopath fear is the emotion that dominates all cerebral activity.

If we bear this fact in mind, many of the phenomena exhibited by it become readily intelligible. Fear, like the other emotions, has a very definite form of physical expression, such as pallor, cries, palpitation of the heart, muscular trembling and relaxation of the sphincters. With these are often associated some voluntary or semi-voluntary movements of a muscle or group of muscles which evidence an attempt on the part of the affrighted individual to escape from a terrifying object or situation. In the youthful psychopath certain of these semi-voluntary defense movements are habitual and constitute the tics with which your clinical experience has familiarized you. The other phenomena are not habitual, but are frequently occasioned, to some degree at least, by various agents which tend to bring the fearemotion to a crisis. These agents are many in number, but the most common are such natural phenomena as thunder and lightning, the noise of fire-arms, high places, crowded or solitary localities and so forth.

The effect of fear upon the child's habit of thought is very striking. The necessary brevity of this paper renders a detailed description of this peculiarity impossible. Suffice it to say that every occurrence that comes to the child's attention and every chance remark that is made within its hearing is seized upon and invested with a personal significance that is always sinister. A single example will illustrate this point. A psychopathic child of six years now under my observation recently heard her father say that in his belief a war between this country and Japan was bound to come. At the time there was no reason to suppose that she had paid any particular attention to what was said, but a few days later, while she was in a down-town store with her mother, she saw two Japanese, and immediately seized her mother's skirts with every evidence of terror. In surprise the mother questioned her closely as to the cause of her fear, and the interrogation finally brought out the fact that the child was convinced that war with Japan had begun and that her life was imperilled by the presence of the Japanese in the store.

The effect of fear upon character formation is equally striking and interesting. In the company of normal children or of adults not of its family, the youthful psychopath is shy and diffident to a marked degree. If its over-exalted sensibilities chance to be wounded by a child of its own age, it invariably has recourse to tears rather than to retaliation. When it is spoken to by grown-ups who are strangers to it, it changes color and stammers out a reply. And when, under observation of which it is conscious, it attempts some performance that calls for nice muscular adjustment, its power of co-ordination is so crippled that the result is a dismal failure.

In the home, on the other hand, this same child is self-willed and domineering. It brooks neither reprimand nor repression, and the slightest contrariety, from no matter what source, calls 
forth an emotional outburst which, in all essential details, corresponds to an hysterical convulsion.

Other striking peculiarities of character are also frequently exhibited. There is no gainsaying the fact that even the most normal child is possessed of a transitory criminality. We are all aware that such a child will lie and steal; that he may be unmoral and without affection; and that he may be cruel to the feeble and to animals. But in the youthful psychopath, owing to its very limited powers of inhibition, these traits are vastly more accentuated, and tend to permanency. In this same child you have the habitual nailbiter and the precocious masturbator, for which peculiarities I have at this time no special explanation to offer.

Permit me to lay emphasis on the fact that all these abnormal characteristics - mental, moral and physical - which mark what I have somewhat inaptly termed the "youthful psychopath," may be brought to light by careful observation and persistent investigation, in subjects between the ages of five and ten years.

Once they are brought to light we may determine by their grouping in a given case whether we are dealing with hysteria or psychasthenia, paranoia or dementia precox; and by their intensity and fixity whether the disorder is merely nascent or in full process of evolution.

All four of these clinical forms present certain features in common, but each is marked by peculiarities that are sufficiently distinctive. In psychasthenia the fear-emotion colors all the mental operations to a certain degree, but the counterbalance of judgment is never lost, so that obsessive ideas are not transformed into delusions; and morbid impulses seldom become overmastering. In paranoia the obsessing ideas tend early to become systematized and to focus upon the subject of the sufferer's personal safety and liberty. Fears which the psychasthenic experiences only in certain places and at certain times, and which lead merely to obsessive ideation, are experienced by the paranoiac at all times and in all places. And instead of obsessions, actual delusions of being followed and persecuted, after a time, completely govern the victim's reaction to his environment.

Dementia precox is to be feared where the powers of inhibition remain markedly weak and the growth of the moral sense does not keep pace with growth in other directions. Here the predatory and animal instincts of the child occupy the foreground of the clinical picture, and we find it to be a shameless liar, a confirmed thief, a natural vagabond, a masturbator and the personification of cruelty.

In the youthful hysteric the obsessive and impulsive tendencies are by no means so marked and obvious as they are in the psychasthenic, the paranoiac and the precocious dement types. The morbid phenomena exhibited by this child are not constant but periodic, and are usually confined to somnambulism and other automatic acts, and to violent emotional outbursts accompanied by convulsive movements, which may be followed by temporary palsy and contracture of limbs or segments of limbs.

After we have determined that we are dealing with a potential or actual victim of some one of the four forms of disorder under consideration, what may we hope to accomplish by treatment? I have already expressed the belief that the underlying morbid condition is a simple adynamic one, but even in a simple adynamic condition of the nervous system we are confronted with a metabolic problem that is by no means easy of solution.

Nervous energy, like electricity, is practically unknowable in essence, and yet we are aware that it is, in part at least, a form of motion liberated from substances with which the body is sustained.

This fact turns our attention at once to the physical needs of the afflicted child. To you who have made such advances in the chemistry of juvenile dietetics, I shall not venture to particularize with regard to food selection. The practical demand is for a diet that offers the highest possible percentage of energy production and is at the same time small in bulk, easy of digestion and assimilation, and inconsiderable in waste.

With the diet problem settled, attention should be turned to faulty postural habits. These defects are best eradicated by participation, enforced if necessary, in outdoor games, which are supervised by a tactful nurse or parent. Regular gymnastic systems are entirely inadvisable because the monotonous repetition of any movement quickly wearies the child both mentally and physically.

When the physical system begins to show signs of increasing vigor, we may safely attempt to divert the child's mental activities into normal channels. This, for several reasons, is the most difficult part of the task. First, because it is oftentimes well-nigh impossible to gain the child's confidence sufficiently to enable one to bring its obsessive ideas to light; second, because the parents themselves are of flabby personality and cannot be made to understand the full significance of the child's condition; and lastly, because environing conditions in general are unfavorable. However, with tact and patience much may be accomplished.

No definite rules can be set down for this portion of the treatment, but the guiding principle should always be disciplinarian in character. The child should never be made to feel that it is any way abnormal and should never be segregated. On the contrary, the social instinct should be fostered and strengthened in every possible way, care being taken that the associations formed are with healthy children. The nipping in the bud of anti-social tendencies is of vital importance, for their persistence in fully developed psychasthenia is a source of the most poignant suffering, and in paranoia a menace to public safety.

The panphobic tendencies of the youthful psychopath must also be eradicated. In this task the personality of the individual in charge of the child counts for everything. Such a person must be fearless, self-repressed, sympathetic yet firm. 
By such qualities the child's confidence is easily won, and it becomes communicative with regard to its fears. When these are known, it should be the aim of the person in charge to rid the child of them by persuasion and by personal example. Ideas of courage in every form should be implanted in the childish imagination and their growth fostered in all possible ways. Depressing tales of a supernatural and terrifying character should be sedulously kept from the child's ears. The threatened invocation of the police or of bogeys for the purpose of checking rebellious tendencies is to be characterized as little short of criminal.

The religious training is also a matter of prime importance and care should be taken to inculcate the notion that the Deity is not revengeful and constantly on the alert for the opportunity to consign His erring children to a material hell.

The importance of both these suggestions becomes manifest when we consider that some of the most distressing fears of the full-fledged psychasthenic center about hobgoblins, supernatural phenomena, the guardians of the law and the wrath of the Creator.

For the ties and for actual convulsive phenomena, the judicious use of sedatives is strongly to be recommended. But for many of the other phenomena exhibited - like stubbornness and temper - I recommend, in spite of the implied heresy, a good, sound spanking.

I am fully aware that I have not covered all the points that a subject such as I have chosen naturally raises. I trust, however, that whatever I have omitted will be fully taken care of in discussion.

In conclusion, permit me to state again my sincere belief that the morbid conditions under consideration are, to the observant, fully obvious at an early period of life and that, by proper treatment, their course may, in many cases, be arrested and many a mental wreck thereby averted.

\section{SOME CLINICO-PATHOLOGICAL DATA ON BLADDER TUMORS.*}

BY LINCOLN DAVIS, M.D., BOBTON.

Aвout four years ago I made a study of 41 cases of tumors of the bladder collected from the records of the Massachusetts General Hospital. ${ }^{1}$ I should like to recapitulate now some of the points made in that analysis, and bring the figures up to date.

In only 28 of these 41 cases were microscopical examinations of the specimens recorded. Twentyfive belonged to the epithelial group, 2 were sarcomata, 1 was a myoma, showing a great preponderance of epithelial tumors. Seventeen of the specimens of epithelial tumors which had been preserved were personally studied; 6 of these showed satisfactory evidence of epithelial infiltration of the bladder wall and were classed as carcinomata; 11, or nearly two thirds, were regarded as papillomata.

* Read before the New England Branch of the American Urologica Association, Nov. 29, 1910.
A total of 37 cases were operated upon, 9 resulting fatally within a month or while still in the hospital, giving an operative mortality of nearly $25 \%$.

In none of the malignant cases was a radical operation, as it is now understood, attempted, but merely such palliative measures as curettage, cauterization and partial removal resorted to, with the result that death from the disease occurred in every case within six months.

Of the 28 patients who survived the operation, 26 were traced. Fourteen, or just $50 \%$, died of the disease, 1 of these surviving for five years in spite of repeated recurrences before finally succumbing. Twelve patients, including those who died of other diseases, had no recurrence so far as could be learned. Nine are known to have survived the operation one year. Seven survived the operation two years. Five survived the operation eight years. Three of the latter died of other diseases, leaving 2 patients living and well at the time of the report, respectively eight and ten years after operation. Of the 5 patients who survived for eight years, in only 3 were there pathological reports on the specimens removed; 1 was a myoma, 2 were papillomata.

Of the 8 cases of papillomata in which the specimens were personally studied, 1 died as the direct result of the operation, 1 died of intercurrent disease eighteen months later without evidence of recurrence, 1 died two months after secondary operation for recurrence, 1 five years later of recurrence. One case reported perfect health one year after operation, not heard from since. One case cannot be traced; one case is well eight years after operation. One case operated on by Dr. A. T. Cabot in 1892 and again in 1897 for recurrence has remained well up to the present time, thirteen years since the second operation.

These figures indicate a considerable period of immunity, if not an ultimate cure, in a respectable proportion of cases of papillomata of the bladder after simple excision of the growth through a suprapubic cystotomy wound.

At the time of writing my former paper on this subject I had a personal operative experience of a single case; since then I have operated on 15 cases of bladder tumors.

Of these more recent cases, 9 were papillomata which showed no evidence of infiltration of the bladder wall as far as microscopical examination of the specimens permitted of determining this point. The tumors varied in size from a large pea to an orange, and in number from a solitary growth to a dozen or more. No recurrences have been reported as yet. Two patients are reported well respectively four and two and one-half years after operation. Four reported themselves as well one year after operation. One case operated on a year ago has not been traced; 2 cases are very recent.

In one case in which there was one large papilloma and five smaller ones, Dr. Whitney's report stated that there was a solid mass of epithelial cells apparently in the lymph spaces 